\title{
En-Route Planning of Multi-Destination Public-Transport Trips Using Smartphones
}

\author{
Subeh Chowdhury and Nasser Giacaman \\ University of Auckland, New Zealand
}

\begin{abstract}
Public transport travelers require well-integrated, real-time information systems to use a network. The objective of this study was twofold: (1) to develop a model to determine the effect of personalized information provision through smartphones on user ability to plan multi-destination trips, and (2) to understand user perception of riding public transport aided by real-time, multi-destination trip-planning smartphone applications. Auckland Pioneer was developed for multi-destination trip planning and integrates real-time public transport services with search functions for places of interest. A test trial was conducted in Auckland, New Zealand, and the findings show the effects of the application on multidestination trip planning in comparison to traditional information sources such as Google Transit. This research contributes to existing literature by demonstrating the importance of personalized information en-route for user multi-destination trip planning. With information to assist trip planning and provide step-by-step guidance en-route, users tend to feel more confident to ride public transport.
\end{abstract}

Keywords: Public transport, mobile applications, mobile devices

\section{Introduction and Research Objectives}

The Intergovernmental Panel on Climate Change has identified improving public transport (PT) systems as a strategy for mitigating issues related to global warming. Commuters' low mode share of PT is a global issue (Buehler and Pucher 2012). For example, in New Zealand, from 2010-2013, only 4.3\% of trips were undertaken using PT (Ministry of Transport 2014). PT also plays a critical role in the attractiveness of a city for tourists; cities with effective and extensive PT networks are potentially more attractive for tourists (Le-Klahn and Hall 2015). To improve PT services globally, transport agencies are upgrading their networks to be more integrated (Chowdhury and Ceder 2013). A key integration element is information integration. An integrated information system is essential to facilitate urban trip planning (Zografos et al. 2008). With many advanced 
PT information systems available, real-time information can be made accessible directly to users en-route (Zhang et al. 2011). One such provision is the use of smartphones to deliver real-time information to travelers en-route.

The aim of this study was to develop a model that demonstrates the impact of planning on multi-destination trips. The effects of a mobile application, Auckland Pioneer, for PT users with smartphones was assessed and, thereby, their perception to ride PT. This application was designed to assist in multi-destination trip planning for travelers with smartphones, both commuters and tourists, by providing the capability to search places of interest. Traditionally, travelers can use online services such as Google Transit or timetables to correlate their places of interest with appropriate PT services. In most cases, such services will provide information in a static scheduled data format and cater only to single-destination trips. If a user wishes to incorporate a journey with multiple destinations and various arbitrary times to spend at each of the intermediate destinations, then the planning becomes more cognitively challenging. The importance of real-time data for planning is clear. Factors such as traffic conditions will render a pre-planned schedule not optimized or, in some cases, invalidated. Auckland Pioneer aims to improve the usability of the PT network by reducing the time spent planning trips and, thereby, overall journey time. An important design feature of Pioneer is that it caters to users undertaking multiple ad-hoc stops en-route to their final destination and allows them to explore unfamiliar areas through a searchable interface integrated with the PT services. The application has been released for Android smartphones in Google Play and integrates sources such as Google Maps for PT route selection and real-time operational data from government agencies such as Auckland Transport. Travelers are able to find places of interest using keywords and are guided step-by-step by the application to reach their destinations. A test trial of the developed application was conducted in Auckland, New Zealand, and a model was developed showing the impact of planning on multi-destination trips.

This paper includes a review of literature, discusses the methodology undertaken to determine the research objectives, provides the results of the simulation and the user survey, offers discussion, and provides a conclusion.

\section{Literature Review}

\section{Need for Real-Time Information}

Although some studies (Zografos et al. 2008, Molin and Chorus 2009) have investigated the need for PT information, relatively less attention has been given to pre-trip information use for planning (Farag and Lyons 2012). The study by Farag and Lyons (2012) found that travelers consult pre-trip PT information more often when making a business trip than a leisure trip. Cebon and Samson (2011) explained that in many cities, services run only somewhat close to printed schedules and, as such, real-time information is required for travelers to make informed decisions. Providing real-time information can assist travelers with trip planning and also can reduce the frequency of operation for service providers (De Borger and Fosgerau 2012). Cherry et al. (2006) discussed that the mapping features of GIS can be used to provide travelers with userspecific routes. Watkins et al. (2010) discussed the importance of web GIS-based trip 
planners and developed the Explore Attraction Search Tool, which searches online databases for places of interest specified by the traveler using keywords; the traveler specifies a starting point along with other trip characteristics and an attraction type such as doctor, bar, park etc., to integrate PT services with attractions. Nelson and Mulley (2013) stated that the use of Intelligent Transport Systems (ITS) for PT information in Australian cities is poor in comparison to European cities. A focus area for the National ITS Strategy for Australia is "traveler information systems," and personalized messaging system through smartphones was identified as a provision.

\section{Examples of Mobile Applications for Navigation}

The use of smartphones has influenced how we spend our personal time and the norms governing human interactions (Berry and Hamilton 2010). A number of recent studies have been conducted to determine the applicability of smartphones for route selection. Navigation systems using smartphones are beneficial for users, as they allow a new market for travelers and providers to attain a large amount of data conveniently.

Gkiotsalitis and Stathopoulos (2014) developed an application that complies with a traveler's preferences and proposes intermodal routes, with the objective to reduce total travel time. The application includes both autos and PT, supports a combination of different means of transport modes, and reduces auto use.

Salcedo and Battistuti (2014) proposed a PT navigation system to find the fastest route in Mexico City's chaotic and uncertain network. The algorithm assessed trip attributes such as transfer time, waiting time, speed of each mode, and time and date of trip to determine the optimal route.

Hung et al. (2012) emphasized the importance of customized navigation systems and developed an application that takes into account traveler preferences to produce the shortest PT route.

Other studies developed navigation systems for travelers with visual disabilities. Huang and Liu (2004) proposed an application that provides contextual information by making use of voice cues of known buildings and landmarks along with directional information. The location of the user is tracked at regular intervals, and the application announces a feature nearest the user's position based on current coordinates.

Korbel et al. (2013) developed a mobile application that retrieves information dependent on user location from PT passenger information systems; the trip planner optimizes travel time and walking distance to the destination.

Many PT operators are implementing smartphone applications globally. In Portugal, the MOVE-ME mobile application can be used by users to navigate the network. Auckland has the AT Public Transport application to assist its commuters. Common applications used in Australia include TransitTime, NextThere, and TripGo. TubeMap in London and RATP in Paris assist travelers with their metro networks. In the U.S., many applications have been developed by PT operators, including DC Metro Rails (Washington, DC), MARTA (Atlanta), TransitGenie (Chicago), Tiramisu (Pittsburgh), and Subway Time (New York) (Global Mass Transit Report 2014). 


\section{Holistic Multi-Destination Planning}

The work presented in this paper differentiates from previous studies by focusing on information integration that supports a holistic approach to planning for multidestination trips. The overarching philosophy is to recognize the complexity of multidestination planning, particularly when travelers require information from multiple sources.

\section{Auckland Pioneer}

Auckland Pioneer was developed by students at the University of Auckland and integrates information from many sources such as Google Transit, Google Directions, Google Search, and real-time information from Auckland Transport (the local PT service provider). Although the application currently uses the local PT service provider for realtime information, the integration of Google Directions web service equips Pioneer with the flexibility to automatically be usable in any city in which information is provided by Google Directions. Using the smartphone's GPS coordinates, the application integrates navigation guidance services (route generation and walking directions) with search functionality to assist users in finding their places of interest by using keywords.

To use Pioneer, it is important to determine a trip's purpose, as this dictates the information requirements. Pioneer acknowledges this by first asking users for the main purpose of the trip, as shown in Figure 1(a). By knowing the purpose for using PT for either a single-destination "planner" or a multi-destination "explorer," the application can immediately hide unnecessary features and simplify its usage in the route planning stage. Whenever available, Pioneer communicates with live data from Auckland Transport for the real-time arrival information of services. Notifications are sent to users throughout their trip, especially when real-time data change.

FIGURE 1.

Main steps in a multidestination exploration

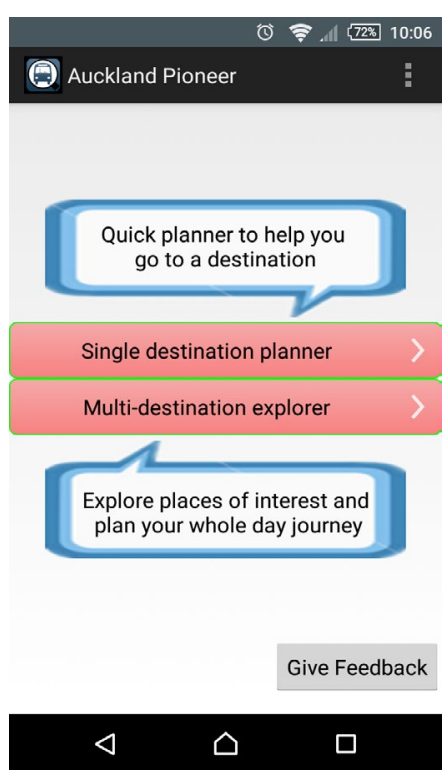

(a)

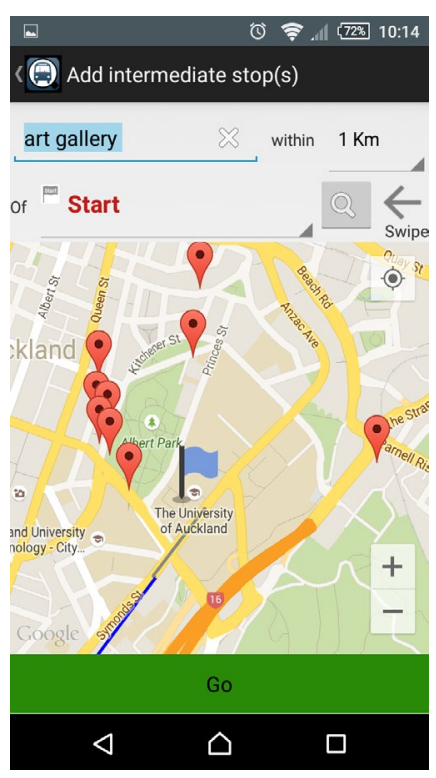

(b)

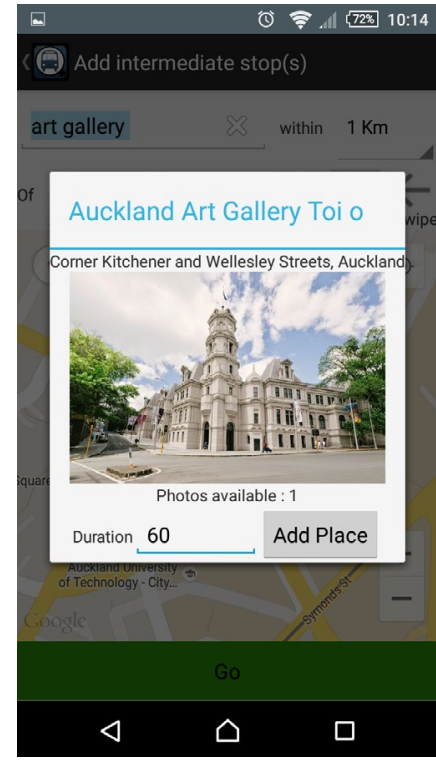

(c) 
FIGURE 1.

(cont'd.)

Main steps in a multidestination exploration

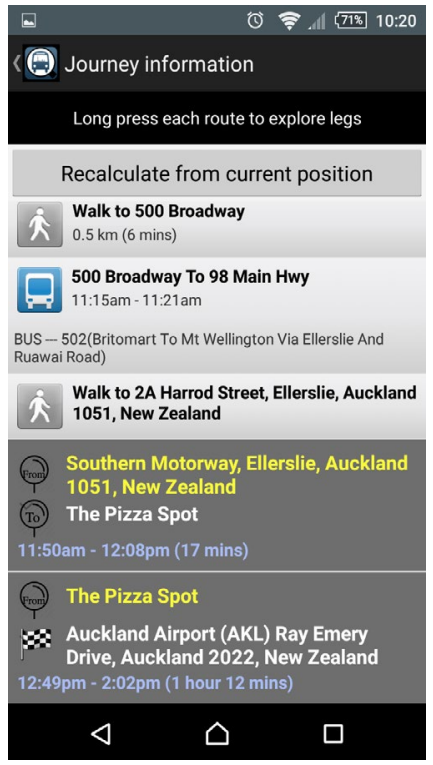

(d)

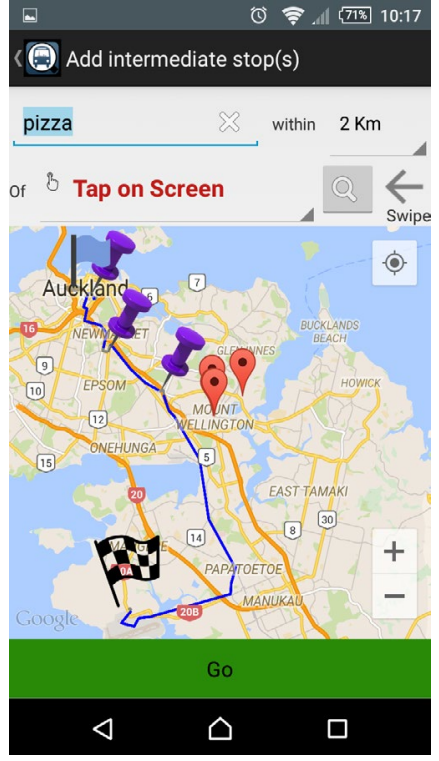

(e)

The feature of Pioneer that distinguishes it from other applications is its exploration functionality. Once users have a preliminary route in place (at least a start and an end), the search function can be used to help plan intermediate stops, targeting users who are exploring (unfamiliar with the location of destinations) while still allowing them to enter addresses of known destinations. A search query is in the form of:

"keyword(s)" within [500m, 1km, 2km, 5km, 10km, 50km] of [Start, End, Tap on Screen]

The predefined radius options represent levels of walking distance $(500 \mathrm{~m}$ and $1 \mathrm{~km}$ for easy walking, or $2 \mathrm{~km}$ and $5 \mathrm{~km}$ for active walkers), as well as more distant ranges (10km and $50 \mathrm{~km}$ ). These distances are centered at predefined points, namely "Start," "End," or "Tap on screen," for flexibility. Figure 1(b) shows an example in which a user is searching for an art gallery within easy walking distance of his/her start location. When the user completes adding intermediate stops, he/she is presented with a high-level overview of the journey, as shown in Figure 1(e). Each entry represents the intermediate trips, where tapping on one will expand the view with more detailed information. GPS tracking helps the user follow the directions on the map.

\section{Model Development}

The main focus of this research was on promoting efficient planning for trips that involve multiple destinations. Although an important aspect is reducing the overall time required in trip planning, another aspect is improving traveler overall in-vehicle experience. For example, by providing a tool that improves the efficiency of pretrip planning, travelers who are prone to motion sickness can relax in-vehicle while maintaining a reasonable overall travel time.

This section presents a simple model that represents traveler planning. The model recognizes that travelers not only are going to multiple destinations but require time at 
each of them (e.g., a tourist sightseeing or a traveler running errands). The notations and their definitions are given as follows:

$n=$ number of destinations in a multi-destination trip (excludes start)

$D_{i}=i^{\text {th }}$ destination in a multi-destination trip, where $D_{0}$ represents the start and $D_{n}$ represents the final destination

$p_{i}=$ planning time incurred at $D_{i}$ in determining how to travel to $D_{i+1}$

$w_{i}=$ waiting time incurred at $D_{i}$ waiting for the vehicle to transport $D_{i+1}$

$v_{i}=$ exemplar in-vehicle travel time to travel from $D_{i}$ to $D_{i+1}$ using public transport

$r_{i}=$ traveler's minimum required time at destination $D_{i}$ (e.g., for errands/ appointments)

$T=$ total time to get from $D_{0}$ to $D_{n}$

$P_{\text {overlap }}=$ total planning time that is overlapped with waiting and/or in-vehicle times

$Q=$ measure of quality for passenger's in-vehicle time not overlapped with planning

Figure 2 shows the model in its simplest form, which assumes that the traveler plans each intermediate destination "one step at a time." Equation 1 gives the total time without any planning overlap.

FIGURE 2.

Example of all time components-travel time $\left(v_{i}\right)$, trip planning $\left(p_{i}\right)$, waiting time $\left(w_{i}\right)$, duration of stay $\left(r_{i}\right)-$ at each destination in a multidestination journey

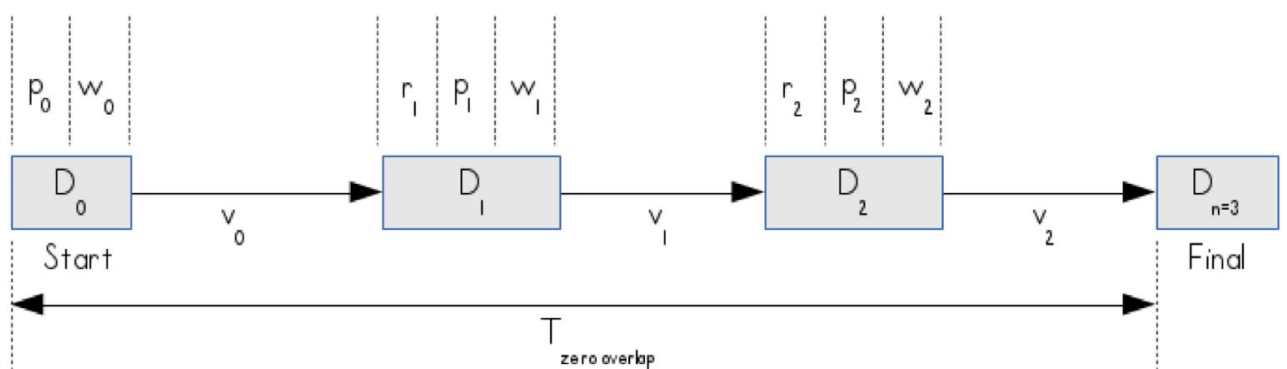

$$
T_{\text {zero overlap }}=\sum_{i=0}^{n-1} v_{i}+\sum_{i=1}^{n-1} r_{i}+\sum_{i=0}^{n-1} p_{i}+\sum_{i=0}^{n-1} w_{i}
$$

However, it is more likely that travelers making multi-destination trips would opt to overlap the planning with other trip components to reduce overall trip time. For example, when a passenger at the "Start" has finished planning his/her route to $D_{1}$ (planning time represented by $\left.p_{0}\right)$, he/she may start to plan $\left(p_{1}\right)$ while waiting $\left(w_{0}\right)$ for a vehicle to $D_{1}$. The traveler can decide to continue this pre-trip planning for successive destinations. This planning overlap may occur at any of the $w_{i}$ or $v_{i}$ components, but never at the $r_{i}$ times of each intermediate destination. Two models represent the overall travel time, depending on when the traveler undertakes the planning: 
- Partial overlap -traveler is either prone to motion sickness or wishes to relax in-vehicle; only planning is overlapped during waiting times (never in-vehicle).

- Maximum overlap -traveler is not prone to motion sickness and decides to plan in-vehicle while in motion.

Further details of the two models is as follows.

\section{Partial Overlap Model}

In the partial overlap model, the amount of time a traveler can save (the overlap amount) is capped depending on the proportion of planning versus waiting time:

- If the waiting time exceeds the planning time, then the passenger saves $\sum_{i=1}^{n-1} p_{i}$ (which corresponds to the planning times of traveling from $D_{1}$ to $D_{n-1}$ ).

- If the planning time exceeds the waiting time, then the passenger saves $\sum_{i=0}^{n-1} w_{i}$ (which corresponds to the waiting times at $D_{0}$ and $D_{n-1}$, inclusively).

Equation 2 provides the partial overlap model, which subtracts this overlap of planning time and waiting time:

$$
\begin{aligned}
\mathrm{T}_{\text {partial overlap }} & =\mathrm{T}_{\text {zero overlap }}-\mathrm{P}_{\text {overlapped with waiting time }} \\
& =\mathrm{T}_{\text {zero overlap }}-\min \left(\sum_{i=1}^{n-1} p_{i}, \sum_{i=0}^{n-1} w_{i}\right)
\end{aligned}
$$

\section{Maximum Overlap Model}

In the maximum overlap model, the amount of time a passenger can save is capped depending on the following:

- If both the waiting and in-vehicle times exceed the planning time, then the passenger saves $\sum_{i=1}^{n-1} p_{i}$ (all planning was undertaken during the waiting and in-vehicle travel times).

- If the planning time exceeds both the waiting and in-vehicle times, then the passenger saves $\sum_{i=0}^{n-1} w_{i}+\sum_{i=0}^{n-1} v_{i}$ (entire waiting and in-vehicle times were fully saturated with planning).

Consequently, Equation 3 shows the maximum overlap model, which subtracts this overlap of planning time and waiting time:

$$
\begin{aligned}
\mathrm{T}_{\text {partial overlap }} & =\mathrm{T}_{\text {zero overlap }}-\mathrm{P}_{\text {overlapped with waiting time }} \\
& =\mathrm{T}_{\text {zero overlap }}-\min \left(\sum_{i=1}^{n-1} p_{i}, \sum_{i=0}^{n-1} w_{i}+\sum_{i=0}^{n-1} v_{i}\right)
\end{aligned}
$$

\section{Pioneer: Holistic Multi-Destination Planning Model}

The primary motivator for this research was to provide travelers with a more holistic approach to multi-destination planning. Searching for arbitrary places of interest, retrieving real-time vehicle information, and map visualization of multiple destinations should all be integrated within the same application. If passengers are equipped with such technology, it is likely they will accomplish the same amount of planning in less time. This model is given in Equation 4, with a factor applied on the planning 
components, as determined from the case study of a participant trial of the application; its impact is evaluated in the model simulation.

$$
T_{\text {Pioneer }}=\sum_{i=0}^{n-1} v_{i}+\sum_{i=1}^{n-1} r_{i}+\text { factor } *\left(\sum_{i=0}^{n-1} p_{i}\right)+\sum_{i=0}^{n-1} w_{i}
$$

\section{In-Vehicle Quality Model}

Whereas passengers following the maximum overlap model will decrease their overall travel time, the model acknowledges that planning is an overhead that is preferred to be avoided and is likely to contribute to passenger discomfort. In-vehicle quality time is defined as the proportion of in-vehicle time that is not used for pre-trip planning time, given in Equation 5:

$$
\begin{aligned}
Q & =\frac{\sum_{i=0}^{n-1} v_{i}-P_{\text {overlapped with in-vehicle travel }}}{\sum_{i=0}^{n-1} v_{i}} \\
& =\frac{\sum_{i=0}^{n-1} v_{i}-\max \left(0, \sum_{i=0}^{n-1} p_{i}-\sum_{i=0}^{n-1} w_{i}\right)}{\sum_{i=0}^{n-1} v_{i}}
\end{aligned}
$$

The amount of planning time that is overlapped in-vehicle is the total planning time less the planning time accomplished while waiting. The model captures the possibilities that the planning was sufficiently undertaken while waiting. It also allows for a negative quality, which is when a large amount of planning could not be accomplished while waiting and in-vehicle. This corresponds to the total journey time being delayed while planning needs to be continued out of vehicle.

\section{Trial and User-Preference Survey}

A trial of Pioneer was conducted at the University of Auckland with Engineering students to determine the effectiveness of the application for multi-destination trip planning and user perception of PT use. An invitation was sent to undergraduate and postgraduate students to participant in a two-day trial. For the trial, 21 students participated, $62 \%$ male and $38 \%$ female and $67 \%$ international and 33\% domestic. All participants were given four routes, two in each set, and a self-administered survey to complete at the end of the trial. Participants were instructed to use Pioneer for one set and to use "conventional" methods of their choice, such as Google Maps, Google Search, printed timetables, or any other application for the other set. Each route had three different intermediate stops. In Route 1 of Set 1, pre-determined intermediate stops with specific addresses were provided. In Route 2 of Set 1, the intermediate destinations were open-ended and determined using keywords and distances (e.g., “Find a pizza place within $500 \mathrm{~m}$ of ..."). The aim of the design of Route 1 was to mimic a scenario of a local user who used the PT network regularly and made errands along the journey from an origin (e.g., home) to a destination (e.g., University of Auckland). Route 2 was designed for explorers (e.g., tourists) and, as such, the intermediate stops included attractions that were searched using keywords. Routes 3 and 4 in Set 2 had different destinations and stops to Routes 1 and 2 , but they were characteristically equivalent. 
Participants were given a form for each route to record their start time, waiting time, vehicle boarding time, arrival time, and planning time for each intermediate destination.

The questionnaire was composed of 16 items, of which 2 were related to participant socio-economic characteristics. The remainder of the questions focused on the usability of Pioneer, participant intentions for future use, and if the application succeeded in reducing their anxiety when exploring unfamiliar areas. Table 1 provides the items and the response scale.

TABLE 1. Questionnaire Components

\begin{tabular}{|c|c|}
\hline Items in Questionnaire & Response Scale \\
\hline Gender & Male/Female \\
\hline Student type & International/Domestic \\
\hline Who do you think Auckland Pioneer will be useful for? & Tourists/Locals/Both \\
\hline $\begin{array}{l}\text { Do you feel the ideas and principles behind Auckland Pioneer are advantageous over other } \\
\text { current travel planning options? }\end{array}$ & Yes/No; reason for response \\
\hline $\begin{array}{l}\text { Personalized information about my journey helped me use the public transport network more } \\
\text { easily. }\end{array}$ & $\begin{array}{l}\text { 5-point Likert Scale (Strongly Disagree to } \\
\text { Strongly Agree) }\end{array}$ \\
\hline $\begin{array}{l}\text { If you were to plan (in the future) a single-destination trip using public transport, would you } \\
\text { use Auckland Pioneer? }\end{array}$ & Yes/No/Maybe; reason for response \\
\hline $\begin{array}{l}\text { If you were to plan (in the future) a multi-destination trip using public transport, would you } \\
\text { use Auckland Pioneer if (a) the exact addresses of all intermediate destination points were } \\
\text { known? (b) a majority of intermediate destinations were unknown and had to be searched for? }\end{array}$ & Yes/No/Maybe; reason for response \\
\hline Did Auckland Pioneer help reduce the amount of time required for planning your routes? & Yes/No/Maybe; reason for response \\
\hline I found the bus/train/trip arrival times reported by Auckland Pioneer to be accurate. & $\begin{array}{l}\text { 5-point Likert Scale (Strongly Disagree to } \\
\text { Strongly Agree) }\end{array}$ \\
\hline Do you think the instructions given for walking are clear? & Very Clear/Average/Not Clear/Not Applicable \\
\hline Did you use the "recalculate from current position" feature? When would you use it? & $\begin{array}{l}\text { Often/Sometimes/Not Applicable; reason for } \\
\text { response }\end{array}$ \\
\hline $\begin{array}{l}\text { Please rank the following features in Auckland Pioneer that you found most useful ( } 1 \text { being } \\
\text { most useful, } 5 \text { being least useful) }\end{array}$ & 6 features of Auckland Pioneer \\
\hline $\begin{array}{l}\text { Auckland Pioneer made me feel more confident about using the public transport network in } \\
\text { unfamiliar areas. }\end{array}$ & $\begin{array}{l}\text { 5-point Likert Scale (Strongly Disagree to } \\
\text { Strongly Agree) }\end{array}$ \\
\hline $\begin{array}{l}\text { Auckland Pioneer helped reduce my anxiety (about how to get there, which bus/train to } \\
\text { catch, how long I have to walk, etc.) when travelling in an unfamiliar area. }\end{array}$ & $\begin{array}{l}\text { 5-point Likert Scale (Strongly Disagree to } \\
\text { Strongly Agree) }\end{array}$ \\
\hline What difficulties did you meet while using Auckland Pioneer? & Open-ended question \\
\hline $\begin{array}{l}\text { What additional features or improvements do you feel would make Auckland Pioneer more } \\
\text { helpful? }\end{array}$ & Open-ended question \\
\hline
\end{tabular}




\section{Results}

\section{Simulation}

A parametric study of the model discussed previously was implemented to simulate the effects of multi-destination trip planning. Figure 3 shows the overall travel times for a passenger constructing a multi-destination trip consisting of five destinations and compares the models of passengers using a non-integrated approach (e.g., using multiple and separate applications such as Google Maps, Google Search, and timetables) with Pioneer. The parameters used closely represent the test trial discussed previously, namely a multi-destination consisting of 5 destinations approximately 20 minutes apart with an average 10-minute wait for the next vehicle. The figure shows how the total trip time increases as the passenger requires more planning time per destination. Based on the 21 participants in the test trial, it was noted that passengers required $35 \%$ less planning time when using Pioneer over the combination of multiple non-integrated applications. A factor of 0.65 was used in the simulation for Pioneer. In addition to the planning application used (Google vs. Pioneer), the two types of users (prone to motion sickness or not) was also distinguished. For users who are not prone to motion sickness, the quality of in-vehicle time reduces as they are consumed by planning in-vehicle. Figure 3 shows that at Point A, passengers using non-integrated applications are limited to 12.5 minutes of planning per destination. If they require more planning per destination, then they will need to either continue their planning in-vehicle (thereby reducing in-vehicle quality) or do the planning out-of-vehicle (thereby increasing overall trip time). With a factor of 0.65 , it can be seen that using Pioneer allows passengers to achieve the equivalent of 20 minutes (an extra 8.5 minutes) of planning per destination.

FIGURE 3.

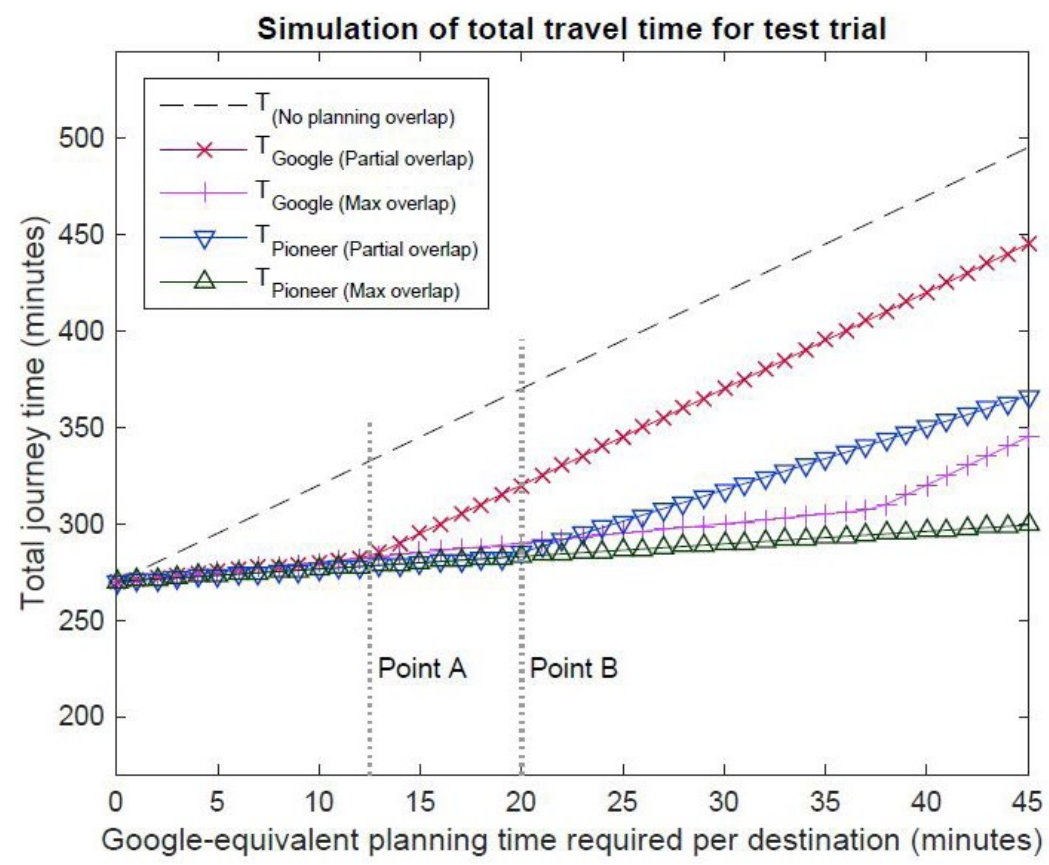


Figures 4(a) and (b) show how the in-vehicle time becomes consumed by planning for passengers willing to plan during this time. The vertical scale on the right represents the in-vehicle time quality, with $100 \%$ representing "good quality" due to no planning in-vehicle and $0 \%$ representing "poor quality" for planning during the entire duration in-vehicle. As more planning is performed in-vehicle, it reduces the passenger's in-vehicle time quality, particularly with lower waiting times (i.e., more frequent PT services). For destinations 20 minutes apart, this occurs when more than 25 minutes of planning is desired but the waiting time is less than 4 minutes. This corresponds to the entire trip (i.e., both waiting and in-vehicle times) being fully consumed with planning and requiring more time while planning is undertaken. This scenario could correspond to a tourist who thoroughly plans in a large city with frequent PT services.

FIGURE 4.

Simulation of quality of in-vehicle time for Google (a) and Pioneer (b)

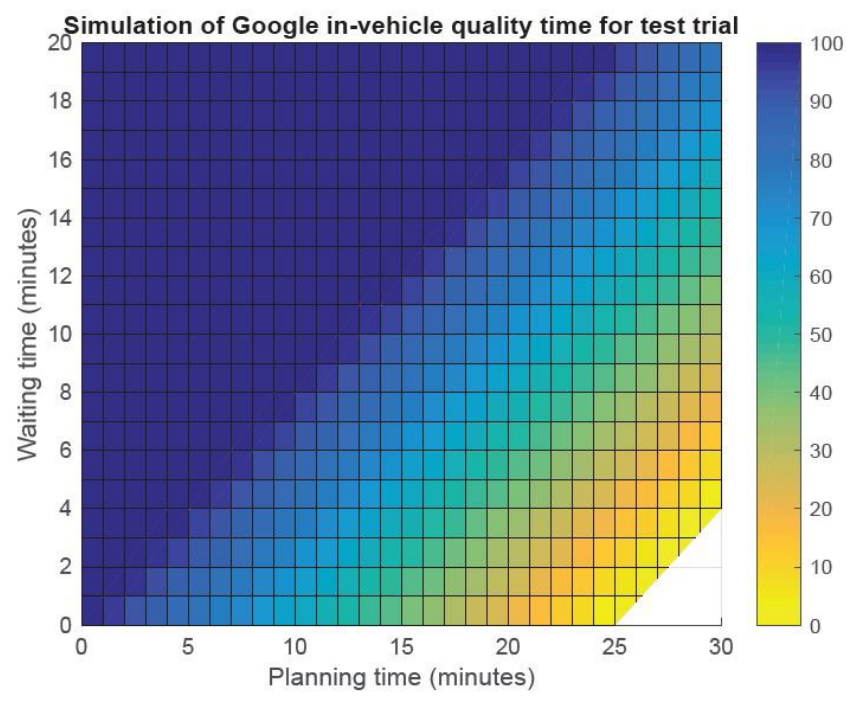

(a)

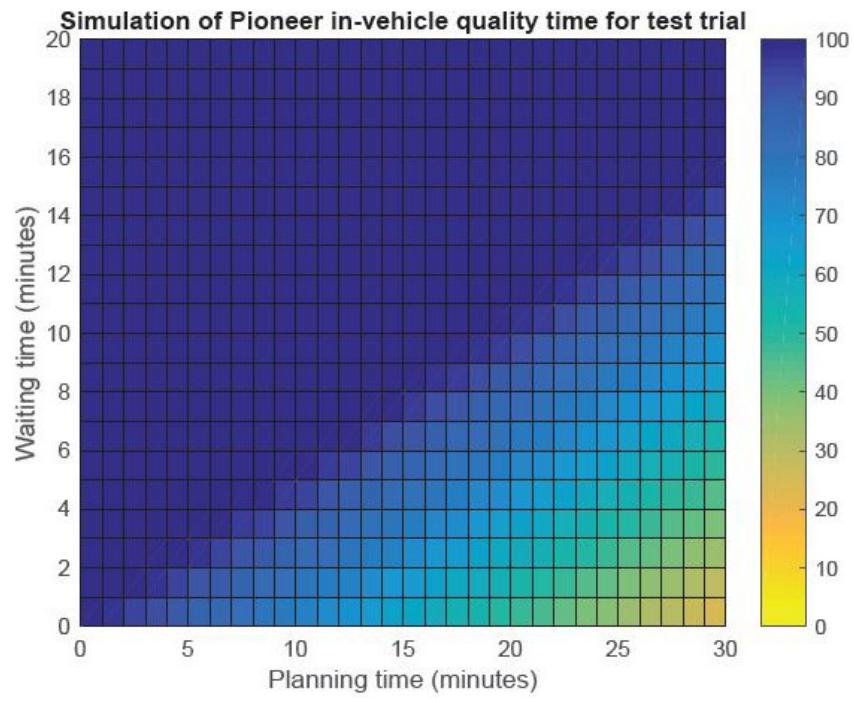

(b) 


\section{User-Preference Survey}

Results showed that the participants found Pioneer to be advantageous over other trip planning provisions for its capability to plan multi-destination trips, and most intended to use the application to plan their future journey with PT. Approximately $80 \%$ intended to use the application given known address of their destinations, and approximately $67 \%$ intended to use Pioneer if the search function is required. Further analysis of the data showed that of the 21 participants, only 1 (a domestic student) denoted that he would not consider using Pioneer when planning a multi-destination trip requiring the entry of known addresses due to the inconvenience resulting from "bugs" when using Pioneer. This is not necessarily a negative statement towards Pioneer, but merely an implementation shortcoming in the current prototype. When it came to performing trip planning with multiple destinations requiring the search function, all participants denoted they would consider using Pioneer.

Three items were used to assess participants' perceived ease of using the PT network given a personalized information system such as Pioneer. Response was measured by a 5-point Likert scale, with 1 being "strongly disagree" and 5 is "strongly agree." Results indicate that Pioneer lowered apprehension and improved the ease of navigating Auckland's PT system. Approximately $67 \%$ of participants selected "agree" or "strongly agree" in response to "Personalized information helped me use the network more easily," and 67\% selected "agree" or "strongly agree" that they felt more confident when traveling in unfamiliar areas; $58 \%$ stated that it reduced anxiety and stress during their journeys. This finding emphasizes the need for personalized information to increase travelers' willingness to use PT, particularly for more intricate multi-destination trips. It supports the findings by Chowdhury and Ceder (2013), which states that high-quality information improves users' control beliefs, leading to a stronger intention-behavior relationship.

Participants were asked to rate the features of Pioneer from most to least useful. The features included real time, multi-destination planning, duration time, search function, walking direction, and route recalculation. In total, $80 \%$ of the participants ranked multi-destination planning as the most useful feature, with another $10 \%$ specifying it as the second most useful. A total of $10 \%$ of the participants specified the feature allowing participants to incorporate duration times within their trip plan as the most useful, with another $45 \%$ specifying it as the second most useful feature. Another notable feature was the integration of the search function as a useful feature (despite the shortcoming with Pioneer's stability), and features such as walking directions and real-time capability were considered less useful in comparison. This helped identify the importance of assisting users in planning complicated multi-destination trips.

\section{Discussion}

Overall, the results of the study demonstrated the importance of personalized information for PT users' multi-destination trip planning. In terms of the cognitive effect of Pioneer on PT use, $80 \%$ of the 21 participants commented that the application reduced the effort required for multi-destination trip planning and assisted with journeys in unfamiliar areas of the city. Features such as specifying durations at each 
intermediate stop and adding multiple destinations throughout the journey eased the creation of user-specific routes for the 21 participants. As for the operation of Pioneer, the application was capable of saving the time taken to plan trips and reduce total travel time. This capability of the application can especially be appreciated by tourists who desire to optimize their limited time in an unfamiliar city; Pioneer allows them to see the "whole picture" in developing their trip plan.

This research contributes to existing literature by demonstrating that real-time, en-route information through smartphone applications that allows exploration features can assist PT users in making multi-destination trips. The main limitation of the study is the small number of participants in the trial. Therefore, the results are indicative and require future research. The proposed approach has been implemented in the form of a free-touse Android application that has been released as an open source software project and allows developers to freely adapt and expand the application for the needs of their city. It also provides researchers with a platform in which they can continue future research on smartphone applications for trip planning.

\section{Conclusion}

Public transport (PT) users require well-integrated information systems to use a network efficiently. Auckland Pioneer was developed for multi-destination trip planning for both commuters and tourists by providing the capability to search places of interest integrated with real-time PT route information. A test trial consisting of 21 participants was conducted at Auckland. A total of $80 \%$ of the 21 participants commented that the application reduced the effort required for multi-destination trip planning and assisted with journeys in unfamiliar areas of the city.

This paper presents two contributions to existing literature. First, the impact of planning is modeled and simulated to emphasize the importance of holistic planning approaches for multi-destination PT trips. Second, the proposed approach has been implemented in the form of a free-to-use Android application and released as an open source software project to allow developers to freely adapt and expand the application for the needs of their city. It also provides researchers with a platform in which they can conduct further research on smartphone applications that provide explorative search features. Overall, results of the study have demonstrated the importance of personalized information en-route for PT user multi-destination trip planning.

\section{References}

Berry, M., and M. Hamilton. 2010. "Changing Urban Spaces: Mobile Phones on Trains." Mobilities, 5(1): 111-129.

Buehler, R., and J. Pucher. 2012.)." Demand for Public Transport in Germany and the USA: An Analysis of Rider Characteristics." Transport Reviews, 32(5): 541-567.

Cebon, P., and D. Samson. 2011. "Using Real Time Information for Transport Effectiveness in Cities." City, Culture and Society, 2: 201-210. 
Cherry, C., M. Hickman, and A. Garg. 2006. "Design of a Map-Based Transit Itenerary Planner." Journal of Public Transportation, 9(2): 45-68.

Chowdhury, S., and A. Ceder. 2013. "Definition of Planned and Unplanned Transfer of Public-Transport Service and Users' Decision to Use Routes with Transfers." Journal of Public Transportation, 16(2): 1-20.

De Borger, B., and M. Fosgerau. 2012. "Information Provision by Regulated Public Transport Companies." Transportation Research Record, 46: 492-510.

Farag, S., and G. Lyons. 2012. "To Use or Not to Use? An Empirical Study of Pre-Trip Public Transport Information for Business and Leisure Trips and Comparison with Car Travel." Transport Policy, 20: 82-92.

Gkiotsalitis, K., and A. Stathopoulos. 2014. "A Mobile Application for Real-Time Multimodal Routing Under a Set of Users' Preferences." Journal of Intelligent Transportation Systems: 1-18.

Global Mass Transit Report. 2014. "Smartphone Applications in Transit Services: Growing Popularity." http://www.globalmasstransit.net/archive.php?id=16210, retrieved September 22, 2015.

Huang, B., and N. Liu. 2004. "Mobile Navigation Guide for the Visually Disabled." Transportation Research Record, 1885: 28-34.

Hung, J. C., A. M. C. Lee, and T. K. Shih. 2012. "Customized Navigation Systems with the Mobile Devices of Public Transport." International Conference of ITS Telecommunications, Taipei, Taiwan.

Korbel, P., P. Skulimowski, P. Wasilewski, and P. Wawrzyniak 2013. "Mobile Applications Aiding the Visually Impaired in Travelling with Public Transport." Federated Conference on Computer Science and Information Systems, Kraków, Poland.

Le-Klahn, D. T., and C. M. Hall 2015. "Tourist Use of Public Transport at Destinations: A Review." Current Issues in Tourism, 18(8): 785-803.

Ministry of Transport. 2014. "Comparing Travel Modes: New Zealand Household Travel Survey 2010-2013." Wellington, New Zealand: 1-19.

Molin, E., and C. Chorus. 2009. "The Need for Advanced Public Transport Information Services When Making Transfers." European Journal of Transport and Infrastructure Research, 4(9): 397-410.

Nelson, J. D., and C. Mulley. 2013. "The Impact of the Application of New Technology on Public Transport Service Provision and the Passenger Experience: A Focus on Implementation in Australia.: Research in Transportation Economics, 39: 300-308.

Salcedo, J. S., and O. C. Battistuti. 2014. "Unscheduled Public Transport Intelligent Navigation System." 18th International Conference on Knowledge-Based and Intelligent Information \& Engineering Systems: 614-623.

Watkins, K. E., B. Ferris, and G. S. Rutherford. 2010. “Explore: An Attraction Search Tool for Transit Trip Planning." Journal of Public Transportation, 13: 111-128. 
Zhang, L., J. Q. Li, K. Zhou, S. D. Gupta, M. Li, W. B. Zhang, M. A. Miller, and J. A. Misener. 2011. "Traveler Information Tool with Integrated Real-Time Transit Information and Multimodal Trip Planning." Transportation Research Record,. 2215: 1-10.

Zografos, K., V. Spitadakis, and K. Androutsopoulos. 2008. "Integrated Passenger Information System for Multimodal Trip Planning." Transportation Research Record, 2072: 20-29.

\section{About the Authors}

SUBeH CHOWdHURY (s.chowdhury@auckland.ac.nz) is a lecturer at the University of Auckland in the Department of Civil and Environmental Engineering. She worked with two international engineering consultancies in New Zealand prior to joining the university in 2014 and has published in reputable journals such as Transport Policy, Journal of Public Transportation, and Journal of Transport Geography.

NASSER GIACAMAN (n.giacaman@auckland.ac.nz) joined as a lecturer in the Department of Electrical and Computer Engineering at the University of Auckland in 2011. He has published in well-known international journals such as the International Journal of Parallel Programming and Parallel Computing. 